\title{
Corrigendum to "The biodiversity cost of reducing management intensity in species-rich grasslands: Mowing annually vs. every third year" [Basic Appl. Ecol. 22 (2017) 61-74]
}

Per Milberg, Malin Tälle, Håkan Fogelfors and Lars Westerberg

The self-archived postprint version of this journal article is available at Linköping University Institutional Repository (DiVA):

http:/ / urn.kb.se/ resolve?urn=urn:nbn:se:liu:diva-146180

N.B.: When citing this work, cite the original publication.

Milberg, P., Tälle, M., Fogelfors, H., Westerberg, L., (2018), Corrigendum to "The biodiversity cost of reducing management intensity in species-rich grasslands: Mowing annually vs. every third year" [Basic Appl. Ecol. 22 (2017) 61-74], Basic and Applied Ecology.

https:// doi.org/ 10.1016/j.baae.2018.02.005

Original publication available at:

https:// doi.org/ 10.1016/j.baae.2018.02.005

Copyright: Elsevier

http:// www.elsevier.com/

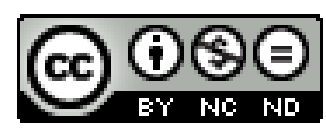


Erratum to "The biodiversity cost of reducing management intensity in species-rich grasslands:

Mowing annually vs. every third year" [Basic Appl. Ecol. 22 (2017) 61-74]

Per Milberga ${ }^{a}$ Malin Tälle ${ }^{a}$, Håkan Fogelfors ${ }^{b}$, Lars Westerberg ${ }^{a}$

a IFM Biology, Conservation Ecology Group, Linköping University, SE-581 83 Linköping, Sweden

${ }^{\mathrm{b}}$ Department of Crop Production Ecology, Swedish University of Agricultural Sciences, Box 7043, SE75007 Uppsala, Sweden

Refers to

Per Milberg, Malin Tälle, Håkan Fogelfors, Lars Westerberg

The biodiversity cost of reducing management intensity in species-rich grasslands: Mowing annually vs. every third year

Basic and Applied Ecology, Volume 22, August 2017, Pages 61-74

The data used to construct Figure 2 had accidentally been mixed up. Two findings reported based on Figure 2A turned out incorrect. Apart from a corrected graph, there are some changes in Results and Discussion. Major conclusions, however, do not change.

Results

First paragraph, second sentence:

Old: The sites showing the weakest effect sizes were the moist one (Gränö, Ekenäs Moist, Andersby), while the drier sites Österplana (dry) and Ekenäs Mesic(dry/mesic) showed the strongest effect sizes (Fig. 2A).

New: There was no apparent relationship between site moisture and the response variables (Fig. 2).

Second paragraph, first sentence:

Old: At least for Fig. 2A, there was an apparent coincidence of the driest sites (Österplana, Ekenäs Mesic) being the ones with the strongest effect sizes while the three moist sites (Gränö, Ekenäs Moist, Andersby) displayed weak effect sizes. Furthermore, there was a tendency for the more species-rich sites to show the stronger effect sizes (linear regression: $P=0.1288$ ).

New: There was no tendency for the more species-rich sites to show the stronger effect sizes (linear regressions; species number $P=0.891$; Shannon $P=0.327$; Shannon evenness $P=0.131$ ), with the exception of Gini-Simpson ( $P=0.040)$.

\section{Discussion}

First paragraph, fifth sentence:

Old: It is also clear that effect sizes were largest in dry sites and smallest in moist sites, and a tendency for the species-rich sites to exhibit larger effect sizes.

New: Sentence deleted 
Figure 2
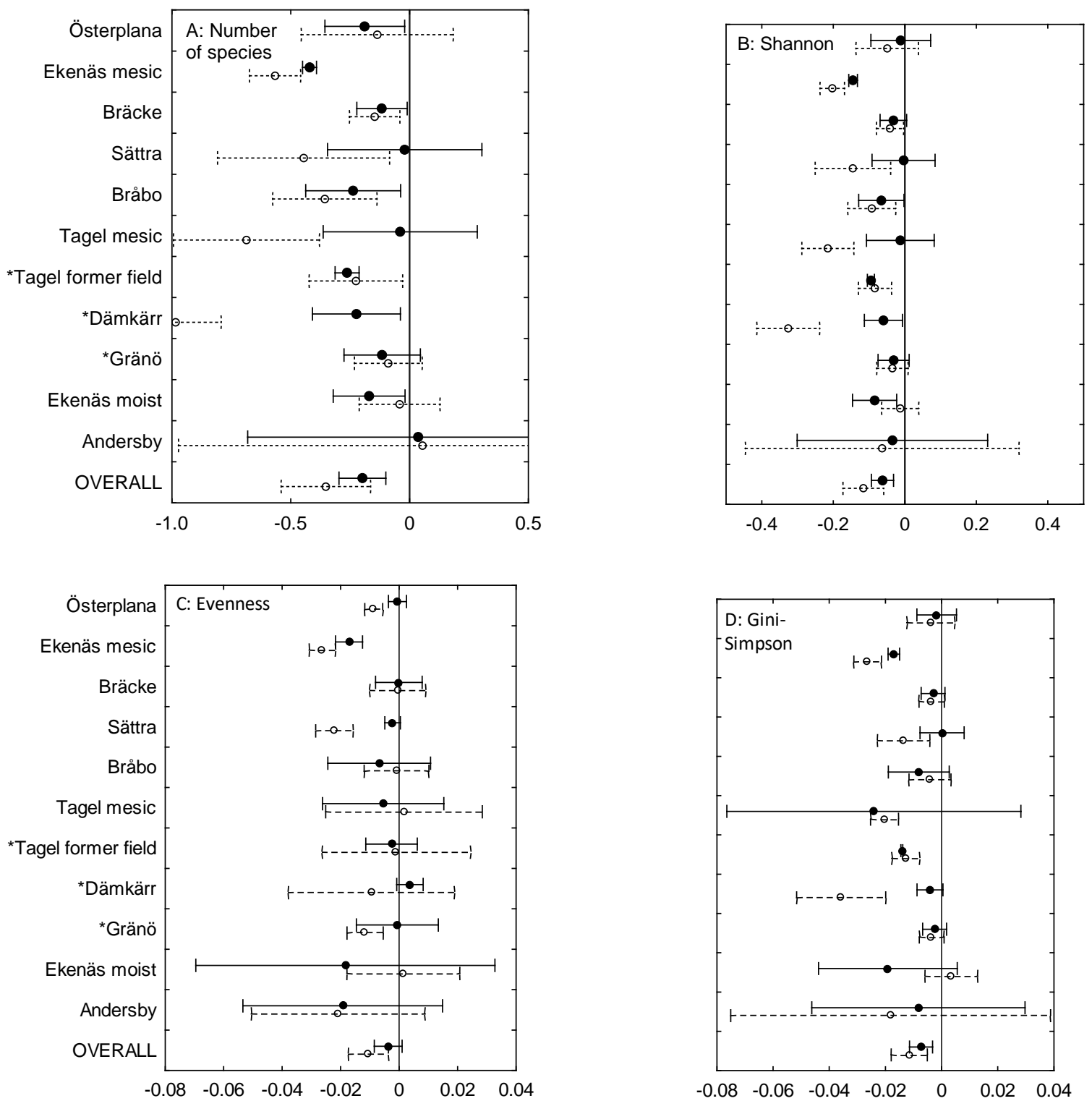

Fig. 2. In(RR-values) for the (A) number of species, (B) Shannon diversity, (C) Shannon evenness, and (D) Gini-Simpson diversity. Trials were run for 11-14 years (see text). A negative value means lower diversity or evenness in mowing every third year (solid symbols, solid bars) or in the untreated control (open symbols, hatched bars), compared with annual mowing. Bars represent $95 \%$ confidence intervals. Note the differences in scale on the $\mathrm{x}$-axes. Trials are ordered from dry/speciesrich to moist/species-poor. Asterisks indicate trials that had been fertilized or abandoned for a few years before the start of the treatment. 